\section{AB1201 INCREASING RATES OF INFLUENZA VACCINATION COVERAGE IN RHEUMATOID ARTHRITIS PATIENTS: DATA FROM A MULTICENTER, LONGITUDINAL COHORT STUDY OF 1,406 PATIENTS}

K. Thomas ${ }^{1}$, A. Lazarini ${ }^{1}$, E. Kaltsonoudis ${ }^{2}$, A. Drosos ${ }^{2}$, A. Repa ${ }^{3}$,

P. Sidiropoulos ${ }^{3}$, K. Fragkiadaki ${ }^{1}$, M. Tektonidou ${ }^{1}$, P. Sfikakis ${ }^{1}$, P. Tsatsani ${ }^{4}$,

S. Gazi ${ }^{4}$, P. Katsimbri ${ }^{1}$, D. Boumpas ${ }^{1}$, E. Argyriou ${ }^{5}$, K. Boki ${ }^{5}$, G. Evangelatos ${ }^{6}$,

A. lliopoulos ${ }^{6}$, K. Karagianni ${ }^{7}$, L. Sakkas ${ }^{7}$, K. Melissaropoulos ${ }^{8}$, P. Georgiou ${ }^{8}$,

E. Grika ${ }^{1}$, P. Vlachoyiannopoulos ${ }^{1}$, T. Dimitroulas ${ }^{9}$, A. Garyfallos ${ }^{9}$,

C. Georganas ${ }^{10}$, P. Vounotrypidis ${ }^{11}$, K. Ntelis ${ }^{12}$, M. Areti ${ }^{13}$, G. D. Kitas ${ }^{1,14}$,

D. Vassilopoulos ${ }^{1}{ }^{1}$ Joint Rheumatology Program, University of Athens Medical School, Athens, Greece; ${ }^{2}$ Rheumatology Clinic, University of loannina, Ioannina, Greece; ${ }^{3}$ Department of Rheumatology, Clinical Immunology and Allergy, University Hospital of Heraklion, Heraklion, Greece; ${ }^{4}$ Rheumatology Unit, KAT Hospital, Athens, Greece; ${ }^{5}$ Rheumatology Unit, Sismanoglio Hospital, Athens, Greece; ${ }^{6}$ Rheumatology Unit, NIMTS Hospital, Athens, Greece; ${ }^{7}$ Department of Rheumatology, University of Thessaly, Larissa, Greece; ${ }^{8}$ Rheumatology Unit, Agios Andreas Hospital, Patras, Greece; ${ }^{9} 4$ th Department of Medicine, Aristotle University, Thessaloniki, Greece; ${ }^{10}$ Private Office, Athens, Greece; ${ }^{11}$ Private Office, Thessaloniki, Greece; ${ }^{12}$ Private Office, Kalamata, Greece; ${ }^{13}$ Private Office, Leivadia, Greece; ${ }^{14}$ Hygeia Hospital, Athens, Greece

Background: Despite the increased incidence of influenza infection in rheumatoid arthritis (RA) patients, vaccination coverage has been shown to be suboptimal. Prospective data regarding the current rate and predictors of influenza vaccination adherence in RA patients are limited.

Objectives: To calculate the current rate and predictors of influenza vaccination in a real-life, prospective, longitudinal RA cohort.

Methods: Data regarding demographics, disease characteristics, treatments and co-morbidities from a multi-center, longitudinal cohort of Greek RA patients were collected at baseline and $\sim 3$ years later. Disease and patient characteristics were compared between patients with at least one influenza vaccine administration and non-vaccinated ones, during the 3 year follow-up period.

Results: From a cohort of 1,569 RA patients, 1,406 with available vaccination data at baseline and 3 years later (mean interval: 2.9 years) were included; (women: $80.4 \%$, mean age: 61.8 years, mean disease duration: 9.7 years, RF and/or anti-CCP positive: $50.4 \%$, mean DAS- $28=3.33$, mean HAQ: 0.44 , bDMARD use: $44.8 \%$ ). At baseline, $54.2 \%$ of patients reported influenza vaccination in the past (31.8\% during the previous season), while during the 3 year follow-up period, $81 \%$ had $\geq 1$ influenza vaccinations $(p=<0.001)$. Patients who received $\geq 1$ influenza vaccine were older ( 63.5 vs. 54.7 years, $p<0.001$ ), were more likely to be seropositive ( $59.2 \%$ vs. $45.2 \%, p<0.001)$, had higher HAQ $(0.46$ vs. $0.36, p=0.02)$ and $B M I(27.7$ vs. $26.9, p=0.02)$ at baseline, more likely to be treated with bDMARDs $(46.8 \%$ vs. $36.4 \%, p<0.001)$ and more likely to have chronic lung disease $(9.7 \%$ vs. $5.3 \%, p=0.02)$, dyslipidemia $(36.4 \%$ vs. $24.2 \%$, $\mathrm{p}<0.001)$, hypertension $(46.1 \%$ vs. $29.2 \%, \mathrm{p}<0.001)$ and to report vaccination against influenza the previous season before baseline evaluation $(34.9 \%$ vs. $18.2 \%, p<0.001)$. By multivariate analysis, history of influenza vaccination during the last season before baseline ( $\mathrm{OR}=1.87, \mathrm{Cl}: 1.27-2.74, \mathrm{p}=0.001)$, bDMARD treatment $(\mathrm{OR}=1.51, \mathrm{Cl}: 1.07-2.13, \mathrm{p}=0.018)$ and age $(\mathrm{OR}=1.05, \mathrm{Cl}: 1.04-1.06$, $p<0.001$ ) were independent predictors of influenza vaccination.

Conclusion: In this ongoing, longitudinal, prospective, real-life RA cohort study, a significant increase in the influenza vaccination coverage was noted (from $53 \%$ to $81 \%$ ). Influenza vaccination was independently associated with recent history of influenza vaccination, older age, and bDMARD treatment.

Acknowledgments: Supported by grants from the Greek Rheumatology Society and Professional Association of Rheumatologists.

Disclosure of Interests: Konstantinos Thomas: None declared, Argyro Lazarini: None declared, Evripidis Kaltsonoudis: None declared, Alexandros Drosos: None declared, ARGYRO REPA: None declared, Prodromos Sidiropoulos: None declared, Kalliopi Fragkiadaki: None declared, Maria Tektonidou Grant/research support from: AbbVie, MSD, Novartis and Pfizer, Consultant of: AbbVie, MSD, Novartis and Pfizer, Petros Sfikakis Grant/research support from: Grant/research support from Abvie, Novartis, MSD, Actelion, Amgen, Pfizer, Janssen Pharmaceutical, UCB, Panagiota Tsatsani: None declared, Sousana Gazi: None declared, Pelagia Katsimbri: None declared, Dimitrios Boumpas: None declared, Evangelia Argyriou: None declared, Kyriaki Boki: None declared, Gerasimos Evangelatos: None declared, Alexios Iliopoulos: None declared, Konstantina Karagianni: None declared, Lazaros Sakkas: None declared, Konstantinos Melissaropoulos: None declared, Panagiotis Georgiou: None declared, Eleftheria Grika: None declared, PANAYIOTIS VLACHOYIANNOPOULOS: None declared, Theodoros Dimitroulas: None declared, Alexandros Garyfallos Grant/research support from: MSD, Aenorasis SA, Speakers bureau: MSD, Novartis, gsk, Constantinos Georganas: None declared, Periklis Vounotrypidis: None declared, Konstantinos Ntelis: None declared, Maria Areti: None declared, George D Kitas: None declared, Dimitrios Vassilopoulos: None declared DOI: 10.1136/annrheumdis-2020-eular.4812

\section{$\mathrm{AB} 1202$ IMPACT OF BIOLOGICAL THERAPY ON WORK ABILITY AND PRODUCTIVITY IN RHEUMATOID ARTHRITIS}

J. Vojinovic ${ }^{1}$, M. Lapcevic ${ }^{2}$, N. Damjanov ${ }^{3}$, M. Sefik Bukilica ${ }^{3}$, D. Loncar ${ }^{4}$, D. Acimovic ${ }^{4}$ on behalf of ORS and URES. ${ }^{1}$ University of Nis, Faculty of Medicine, Nis, Serbia; ${ }^{2}$ Association of Patients with Rheumatic Diseases ORS, Belgrade, Serbia; ${ }^{3}$ Institute of Rheumatology, Belgrade, Serbia; ${ }^{4}$ University of Belgrade, Faculty of Economics, Belgrade, Serbia

\section{Background:}

Objectives: The objective of the study was to determinate the perceived impact of biological therapy on work ability and productivity of RA patients in Republic of Serbia.

Methods: The analysis was based on questionnaires filled by 626 patients treated with biological therapy and 175 patients treated with conventional therapy, as well as on information gathered on four focus groups. Two monetized indicators were used in the study: Work Productivity and Activity Impairment Questionnaire General Health V2.0 (WPAl-GH) and Human Capital Approach (HCA), as well as two non-monetized indicators: Stanford Presenteeism Scale (SPS) and The Health and Work Performance Questionnaire (HPQ). The use of WPAl-GH indicator on gathered data helps calculate the total cost of decreased productivity caused by RA, based on two complementary aspects: absenteeism and presenteeism. The HCA indicator builds on costs measured by WPAI-GH, by providing information on the cost of work disability caused by RA, as the cost that resulted from early retirement of patients. SPS provides the foundation for comparison of subjective feeling regarding the impact of RA on performing work tasks between patients treated with biological therapy and patients treated with conventional therapy, using Mann-Whitney test. HPQ indicator provides the basis for comparison of non-monetized absenteeism and presenteeism, in both absolute and relative terms, between the two groups of patients.

Results: Our results showed that the total cost of lost productivity of working population with RA in Serbia amounts 2.6 billion RSD (22.2 million EUR), while the total cost of work disability is 15.3 billion RSD (130.8 million EUR) per annum. Results of the HPQ analysis showed that the group treatedetd with conventional therapy had been absent from their work three times more frequently, on average, than the patients treated with biological therapy. Also, the group of patients treated with conventional therapy rated their work performance as lower than average - they rated their productivity as $94.21 \%$ of average productivity of other employees at the same/similar job, while the group treated with biological therapy rated themselves as equally productive, compared to other employees. SPS analysis details are presented in Table (Mann-Whitney test).

\begin{tabular}{|c|c|c|c|c|c|}
\hline & $\begin{array}{c}\text { Biological } \\
\text { therapy } \\
\text { (Yes/No) }\end{array}$ & $\mathrm{N}$ & $\begin{array}{l}\text { Mean } \\
\text { Rank }\end{array}$ & $\begin{array}{l}\text { Sum of } \\
\text { Ranks }\end{array}$ & $\begin{array}{c}\text { p value } \\
\text { (signif- } \\
\text { icance } \\
\text { level: } \\
0.05 \text { ) }\end{array}$ \\
\hline $\begin{array}{l}\text { Despite having my health problem, I was able } \\
\text { to finish all tasks in my work. }\end{array}$ & $\begin{array}{c}0 \\
1 \\
\text { Total }\end{array}$ & $\begin{array}{c}56 \\
208 \\
264\end{array}$ & $\begin{array}{l}113.61 \\
137.59\end{array}$ & $\begin{array}{c}6362.00 \\
28618.00\end{array}$ & 0.027 \\
\hline $\begin{array}{l}\text { At work, I was able to focus on achieving my } \\
\text { goals despite my health problem. }\end{array}$ & $\begin{array}{c}0 \\
1 \\
\text { Total }\end{array}$ & $\begin{array}{l}55 \\
206 \\
261\end{array}$ & $\begin{array}{r}110.43 \\
136.49\end{array}$ & $\begin{array}{l}6073.50 \\
28117.50\end{array}$ & 0.016 \\
\hline $\begin{array}{l}\text { Despite having my health problem, I felt ener- } \\
\text { getic enough to complete all my work. }\end{array}$ & $\begin{array}{c}0 \\
1 \\
\text { Total }\end{array}$ & $\begin{array}{c}56 \\
206 \\
262\end{array}$ & $\begin{array}{l}112.64 \\
136.63\end{array}$ & $\begin{array}{c}6308.00 \\
28145.00\end{array}$ & 0.03 \\
\hline $\begin{array}{l}\text { Because of my health problem, the stresses } \\
\text { of my job were much harder to handle. }\end{array}$ & $\begin{array}{c}0 \\
1 \\
\text { Total }\end{array}$ & $\begin{array}{l}56 \\
204 \\
260\end{array}$ & $\begin{array}{l}152.51 \\
124.46\end{array}$ & $\begin{array}{r}8540.50 \\
25389.50\end{array}$ & 0.01 \\
\hline $\begin{array}{l}\text { My health problem distracted me from taking } \\
\text { pleasure in my work. }\end{array}$ & $\begin{array}{c}0 \\
1 \\
\text { Total }\end{array}$ & $\begin{array}{c}56 \\
205 \\
261\end{array}$ & $\begin{array}{l}161.55 \\
122.65\end{array}$ & $\begin{array}{c}9047.00 \\
25144.00\end{array}$ & 0.00 \\
\hline $\begin{array}{l}\text { I felt hopeless about finishing certain work } \\
\text { tasks, due to my health problem. }\end{array}$ & $\begin{array}{c}0 \\
1 \\
\text { Total }\end{array}$ & $\begin{array}{c}56 \\
208 \\
264\end{array}$ & $\begin{array}{l}155.34 \\
126.35\end{array}$ & $\begin{array}{l}8699.00 \\
26281.00\end{array}$ & 0.01 \\
\hline
\end{tabular}

Conclusion: Analysis undoubtedly suggests that RA influences lost productivity costs and work disability. Both work ability and productivity are better when biological therapy is in use, why significant savings would be possible if access to biological therapy could be used at an earlier stage of disease.

Disclosure of Interests: Jelena Vojinovic Consultant of: Roche, Abbvie, Pfizer, MSD, Speakers bureau: Roche, Abbvie, Pfizer, MSD, Mirjana Lapcevic: None declared, Nemanja Damjanov Grant/research support from: from AbbVie, Pfizer, and Roche, Consultant of: AbbVie, Gedeon Richter, Merck, Novartis, Pfizer, and Roche, Speakers bureau: AbbVie, Gedeon Richter, Merck, Novartis, Pfizer, and Roche, Mirjana Sefik Bukilica: None declared, Dragan Loncar: None declared, Danica Acimovic: None declared

DOI: 10.1136/annrheumdis-2020-eular.3892 